Research Article

\title{
Prediction of Surface Roughness in End Milling Of P20 Mould Steel Using Artificial Neural Networks
}

\author{
B. Sidda Reddy ${ }^{1, *}$, N. Jaya Krishna ${ }^{1}$, J. Suresh Kumar ${ }^{2}$ and K. Vijaya Kumar Reddy ${ }^{2}$ \\ ${ }^{I}$ K.L.College of Engineering, Vaddeswaram-522502, Dept. of EEE, Andhra Pradesh, India. \\ ${ }^{2}$ M.J College of Engineering and Technology, Hyderabad-500034, Dept. of EEE, Andhra Pradesh, India.
}

Received 7 July 2011; Accepted 1 February 2012

\begin{abstract}
In this paper, an attempt has been made to develop an accurate mathematical model for predicting the surface roughness in end milling of P20 mould steel using artificial neural networks (ANN). For training and testing of the ANN model, a number of experiments have been carried out using Taguchi's orthogonal array in the design of experiments (DOE). The cutting parameters used are nose radius, cutting speed, cutting feed, axial depth of cut and radial depth of cut. The ANN model was developed using multilayer perceptron (MLP) network for nonlinear mapping between the input and the output parameters. The adequacy of the developed model is verified using coefficient of determination (R). It was found that the $\mathrm{R}^{2}$ value is 1 for surface roughness. To judge the ability and efficiency of the ANN model, percentage deviation and average percentage deviation has been used. The research showed acceptable prediction results for the ANN model.
\end{abstract}

Keywords: P20 mould steel, Design of Experiments, Artificial Neural Networks, MLP.

\section{Introduction}

Milling is the most common form of machining process used in the production of moulds/dies, due to the high tolerances and surface finishes by cutting away the unwanted material. The selection of Pre-hardened steel (P-20) is widely used in production of molds/dies because of less wear-resistant and are used for large components. In the past, Abbas Fadhel Ibraheem et al. [1] investigated the effect of cutting speed, feed, axial and radial depth of cut on cutting force in machining of modified AISI P20 tool steel in end milling process. They concluded that, higher the feed rates, larger the cutting forces. They also developed the genetic network model to predict the cutting forces. Muammer Nalbant et al. [2] used the multiple regression analysis and artificial neural network models for predicting the surface roughness in turning of AISI 1030 steel material. These techniques used full factorial design and analysis of variance (ANOVA). According to them, Surface roughness increases with increase of feed rate but decreases with increase of insert nose radius. Ekanayake and Mathew [3] investigated the effect of cutting speed, feed and depth of cut on cutting forces with different inserts while milling AISI1020 steel. According to them, the tool offsets and run-outs affect significantly on the cutting forces when it comes to high speed milling, where small cut sections are employed. This can cause uneven wear of the tool tips due to uneven chip loads. Lajis et al. [4] developed the response surface model to predict the tool life in end milling of hardened steel AISI

\footnotetext{
*E-mail address: bsrrgmcet@gmail.com

ISSN: 1791-2377 @ 2012Kavala Institute of Technology. All rights reserved.
}

D2. This technique used central composite design in the design of experiments and ANOVA. The objective was to obtain the contribution percentages of the cutting parameters (cutting speed, feed and depth of cut) on the tool life. Richard Dewes et al. [5] carried out the study on rapid machining of hardened AISI H13 and D2 moulds, dies and press tools. The primary objective was to assess the drilling and tapping of AISI D2 and H13 with carbide cutting tools, in terms of tool life, workpiece quality, productivity and costs. The secondary aim was to assess the performance of a number of water-based dielectric fluids, intended primarily for EDM operations, against a standard soluble oil cutting fluid, in order to assess the feasibility of a duplex machining arrangement involving HSM and EDM on one machine tool. Mohammad Reza Soleymani Yazdi and Saeed Zare Chavoshi [6] studied the effect of cutting parameters and cutting forces on rough and finish surface operation and material removal rate (MRR) of AL6061 in CNC face milling operation. The objective was to develop the multiple regression analysis and artificial neural network models for predicting the surface roughness and material removal rate. According to them, in rough operation, the feed rate and depth of cut are the most significant effect parameters on $R_{a}$ and MRR and increases with the increase of the cutting forces. Abou-El-Hossein et al. [7] developed the model for predicting the cutting forces in an end milling operation of modified AISI P20 tool steel using the response surface methodology (RSM). Khalid Hafiz et al. [8] developed the response surface model to predict the tool life in end milling of hardened steel AISI H13 hardened tool steel. This technique used central composite design in the design of experiments and ANOVA. The objective was to obtain the 
contribution percentages of the cutting parameters (cutting speed, feed and depth of cut) on the tool life. Rahman et al. $[9,10]$ compared the machinability of the P20 mould steel (357 HB) in dry and wet milling conditions. They considered a range of $75-125 \mathrm{~m} / \mathrm{min}$ for the cutting speed and a feed ranging between 0.3 and $0.7 \mathrm{~mm} /$ tooth: they found the cutting forces in both processes to be similar, but with the flank wear acceleration higher in dry milling. Furthermore, they observed a better surface finish with wet milling. Liao and Lin [11] studied the milling process of P20 steel with MQL lubrication. The cutting speeds were from $200-500 \mathrm{~m} / \mathrm{min}$ and the feed between $0.1-0.2 \mathrm{~mm} /$ tooth. The authors found that the tool life is higher with MQL, due to an oxide layer formed on the tool inserts that helped to lengthen the tool life.

In the present work an attempt has been made to develop the artificial neural network model to predict the surface roughness in end milling of P20 steel by considering the input parameters such as cutting speed, feed rate, axial-depth of cut, radial depth of cut and nose radius. The developed model is tested using test data. The predicted results were analyzed through experimental verification. To have more precise investigation in to the models, a regression analysis of experimental and predicted outputs was preformed. It was found that the $R_{2}$ value is 1 for surface finish. To judge the ability efficiency of the developed model, percentage deviation and average percentage deviation has been used.

\section{P20 Mould Steel Material}

The workpiece material used for the present investigation is P20 mould steel of flat work pieces of $100 \mathrm{~mm} \times 100 \mathrm{~mm}$ $\times 10 \mathrm{~mm}$ and the density of the material in metric units is $7.8 \mathrm{~g} / \mathrm{cc}$. The chemical composition of the workpiece material is given in the Table 1 .

Table 1. Chemical composition of P20 mould steel

\begin{tabular}{ll}
\hline Composition & Weight (\%) \\
\hline Carbon & $0.35-0.45$ \\
Silicon & $0.2-0.4$ \\
Manganese & $1.3-1.6$ \\
Chromium & $1.8-2.1$ \\
Molybdenum & $0.15-0.25$ \\
\hline
\end{tabular}

\section{Artificial neural networks}

The use of artificial neural networks (ANN) has been well accepted in the areas of telecommunication, signal processing, pattern recognition, prediction, process control and financial analysis. Artificial neural networks which are simplified models of the biological neuron system, is a massively parallel distributing processing system made up of highly interconnected neural computing elements or processing units is called neurons. Neural networks are built by connecting these neurons together by weighted inter connections. Determination of these weights called training is the most significant task. In supervised learning the network is trained to learn a mapping from certain inputs to given outputs. An example of supervised learning is the back propagation method for multilayer perceptron (MLP) networks. Multilayer means the addition of one or more hidden layers in between the input and output layers. In the network each neuron receives total input from all of the neurons in the preceding layer according to the Eq. (1).

$$
\text { net }_{j}=\sum_{j=0}^{N} W_{i j} X_{i}
$$

where net ${ }_{j}$ is the total or net input and $\mathrm{N}$ is the number of inputs to the $\mathrm{j}^{\text {th }}$ neuron in the hidden layer. $\mathrm{W}_{\mathrm{ij}}$ is the weight of the connection from the $i^{\text {th }}$ neuron in the forward layer to the $\mathrm{j}^{\text {th }}$ neuron in the hidden layer. A neuron in the network produces its output (Out ${ }_{j}$ ) by processing the net input through an activation (Transfer) function, such as sigmoidal function as in Eq. (2).

$$
\text { Out } \left._{j}=\mathrm{f}^{\text {net }} \mathrm{j}\right)=\frac{1}{1+\mathrm{e}^{- \text {net }}}
$$

In the training process the algorithm is used to calculate neuronal weights, so that the squared error between the calculated outputs and observed outputs from the training set is minimum and is calculated using Eq. (3).

$$
E=\sum_{i} \sum_{i}\left(d_{i}-y_{i}\right)^{2}
$$

where $d_{i}$ is the desired response (or target signal), $y_{i}$ are the output units of the network, and the sums run over time and over the output units. When the mean square error is minimized, the power of the error (i.e. the power of the difference between the desired and the actual ANN output) is minimized [12].

\section{Experimental details}

The design of experiments (DOE) technique has been implemented to conduct the experiments. It is a powerful work tool which allows us to model and analyse the influence of determined process variables over the specified variables, which are usually known as response variables. These response variables are unknown functions of the former design variables, which are also known as design factors. Within the design of experiments, there are various types that can be considered. One of the most widely known ones is the orthogonal array design. In this study, the surface roughness of P20 mould steel material was investigated by considering the process parameters, nose radius, cutting speed, cutting feed, axial depth of cut and radial depth of cut. Therefore, a DOE setup was considered, nose radius with two levels and cutting speed, cutting feed, axial depth of cut and radial depth of cut with five levels each and then $2 \times 5 \times 5 \times 5 \times 5=1250$ runs were required in the experiments for five independent variables. But using Taguchi's orthogonal array the number of experiments reduced to 50 experiments from 1250 experiments. All the experiments were conducted on CNC Vertical milling machine 600 II as shown in Figure 1. The specifications of the Vertical milling machine are: The tool holder used for milling operation was KENAMETAL tool holder BT40ER40080M, Table clamping area: 20 TOOLS ATC STANDARD, Maximum load on the table: $700 \mathrm{kgs}$, Spindle taper: BT-40, Spindle speeds range:8-8000 rpm, Power: $13 \mathrm{~kW}$, Feed rates range: $0-12 \mathrm{~m} / \mathrm{min}$ and the too material used for the present study 
was coated carbide cutting tool. The machining parameters used and their levels chosen are presented in Table 2.

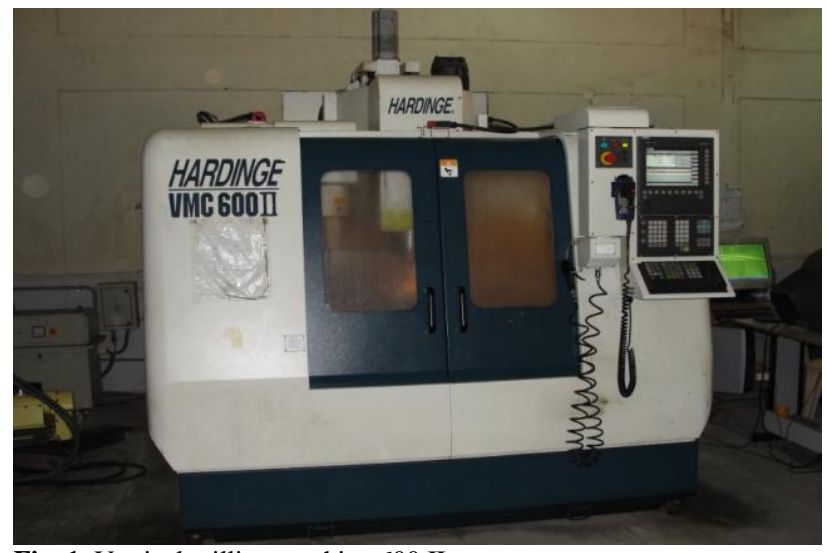

Fig. 1. Vertical milling machine $600 \mathrm{II}$

Table 2. Machining parameters and their levels

\begin{tabular}{llllllll}
\hline $\begin{array}{l}\text { Machining } \\
\text { parameter }\end{array}$ & Units & \multicolumn{5}{l}{ Symbol Level1Level2Level3Level4Level 5 } \\
$\begin{array}{llllllll}\text { Nose } \\
\text { radium }\end{array}$ & $\mathrm{mm}$ & $\mathrm{R}$ & 0.8 & 1.2 & - & - & - \\
$\begin{array}{l}\text { Cutting } \\
\text { speed }\end{array}$ & $\mathrm{m} / \mathrm{min}$ & $\mathrm{V}$ & 75 & 80 & 85 & 90 & 95 \\
$\begin{array}{l}\text { Feed rate } \\
\mathrm{mm} / \text { tooth }\end{array}$ & $\mathrm{f}$ & 0.1 & 0.125 & 0.15 & 0.175 & 0.2 \\
$\begin{array}{l}\text { Axial depth of } \\
\text { cut }\end{array}$ & $\mathrm{mm}$ & $\mathrm{d}$ & 0.5 & 0.75 & 1 & 1.25 & 1.5 \\
$\begin{array}{l}\text { Radial depth of } \\
\text { cut }\end{array}$ & $\mathrm{rd}$ & 0.3 & 0.4 & 0.5 & 0.6 & 0.7 \\
\hline
\end{tabular}

The average surface roughness $\left(\mathrm{R}_{\mathrm{a}}, \mu \mathrm{m}\right)$ which is mostly used in industrial environments is taken up for the present study. The average surface roughness is the integral absolute value of the height of the roughness profile over the evaluation length and was represented by the Eq. (4).

$\mathrm{R}_{\mathrm{a}}=\frac{1}{\mathrm{~L}} \int_{0}^{\mathrm{L}}|\mathrm{Y}(\mathrm{x}) \mathrm{dx}|$

where $\mathrm{L}$ is the length taken for observation and $\mathrm{Y}$ is the ordinate of the profile curve. The surface roughness was measured by using Surtronic $3^{+}$stylus type instrument manufactured by Taylor Hobson with the following specifications. Traverse Speed: $1 \mathrm{~mm} / \mathrm{sec}$, Cut-off values $0.25 \mathrm{~mm}, 0.80 \mathrm{~mm}$ and $2.50 \mathrm{~mm}$, Display LCD matrix, Battery Alcaline 600 measurements of $4 \mathrm{~mm}$ measurement length. The actual setting values for the design matrix [12] and experimental results are shown in Table 3.

\section{Development of ANN model for predicting the surface finish}

One of the key issues when designing a particular neural network is to calculate proper weights for neuronal activities. These are obtained from the training process applied to the given neural network. To that end, a training sample is provided, i.e. a sample of observations consisting of inputs and their respective outputs. The observations are fed to the network. In the training process the algorithm is used to calculate neuronal weights, so that the squared error between the calculated outputs and observed outputs from the training set is minimized [13].

Table 3. Training data set used in creating ANN model

\begin{tabular}{|c|c|c|c|c|c|c|}
\hline S.No & $\mathbf{R}$ & V & f & d & rd & $\begin{array}{l}\text { Measured } \\
\text { Surface } \\
\text { roughness } \\
\left(\mathbf{R}_{\mathrm{a}}, \mu \mathrm{m}\right)\end{array}$ \\
\hline 1 & 0.8 & 75 & 0.1 & 0.5 & 0.3 & 0.94 \\
\hline 2 & 0.8 & 75 & 0.125 & 0.75 & 0.4 & 1.16 \\
\hline 3 & 0.8 & 75 & 0.15 & 1 & 0.5 & 1.12 \\
\hline 4 & 0.8 & 75 & 0.175 & 1.25 & 0.6 & 0.86 \\
\hline 5 & 0.8 & 75 & 0.2 & 1.5 & 0.7 & 0.66 \\
\hline 6 & 0.8 & 80 & 0.1 & 0.75 & 0.5 & 0.82 \\
\hline 7 & 0.8 & 80 & 0.125 & 1 & 0.6 & 1.44 \\
\hline 8 & 0.8 & 80 & 0.15 & 1.25 & 0.7 & 0.7 \\
\hline 9 & 0.8 & 80 & 0.175 & 1.5 & 0.3 & 0.92 \\
\hline 10 & 0.8 & 80 & 0.2 & 0.5 & 0.4 & 1.28 \\
\hline 11 & 0.8 & 85 & 0.1 & 1 & 0.7 & 1.08 \\
\hline 12 & 0.8 & 85 & 0.125 & 1.25 & 0.3 & 1.3 \\
\hline 13 & 0.8 & 85 & 0.15 & 1.5 & 0.4 & 1.48 \\
\hline 14 & 0.8 & 85 & 0.175 & 0.5 & 0.5 & 1.44 \\
\hline 15 & 0.8 & 85 & 0.2 & 0.75 & 0.6 & 1.54 \\
\hline 16 & 0.8 & 90 & 0.1 & 1.25 & 0.4 & 0.56 \\
\hline 17 & 0.8 & 90 & 0.125 & 1.5 & 0.5 & 0.46 \\
\hline 18 & 0.8 & 90 & 0.15 & 0.5 & 0.6 & 0.42 \\
\hline 19 & 0.8 & 90 & 0.175 & 0.75 & 0.7 & 0.58 \\
\hline 20 & 0.8 & 90 & 0.2 & 1 & 0.3 & 0.5 \\
\hline 21 & 0.8 & 95 & 0.1 & 1.5 & 0.6 & 0.46 \\
\hline 22 & 0.8 & 95 & 0.125 & 0.5 & 0.7 & 1.1 \\
\hline 23 & 0.8 & 95 & 0.15 & 0.75 & 0.3 & 0.86 \\
\hline 24 & 0.8 & 95 & 0.175 & 1 & 0.4 & 0.48 \\
\hline 25 & 0.8 & 95 & 0.2 & 1.25 & 0.5 & 0.74 \\
\hline 26 & 1.2 & 75 & 0.1 & 0.5 & 0.6 & 0.98 \\
\hline 27 & 1.2 & 75 & 0.125 & 0.75 & 0.7 & 1.2 \\
\hline 28 & 1.2 & 75 & 0.15 & 1 & 0.3 & 1.68 \\
\hline 29 & 1.2 & 75 & 0.175 & 1.25 & 0.4 & 1.06 \\
\hline 30 & 1.2 & 75 & 0.2 & 1.5 & 0.5 & 0.52 \\
\hline 31 & 1.2 & 80 & 0.1 & 0.75 & 0.3 & 1.14 \\
\hline 32 & 1.2 & 80 & 0.125 & 1 & 0.4 & 2.48 \\
\hline 33 & 1.2 & 80 & 0.15 & 1.25 & 0.5 & 1.74 \\
\hline 34 & 1.2 & 80 & 0.175 & 1.5 & 0.6 & 1.48 \\
\hline 35 & 1.2 & 80 & 0.2 & 0.5 & 0.7 & 1.72 \\
\hline 36 & 1.2 & 85 & 0.1 & 1 & 0.5 & 0.52 \\
\hline 37 & 1.2 & 85 & 0.125 & 1.25 & 0.6 & 0.92 \\
\hline 38 & 1.2 & 85 & 0.15 & 1.5 & 0.7 & 0.76 \\
\hline 39 & 1.2 & 85 & 0.175 & 0.5 & 0.3 & 0.64 \\
\hline 40 & 1.2 & 85 & 0.2 & 0.75 & 0.4 & 0.96 \\
\hline 41 & 1.2 & 90 & 0.1 & 1.25 & 0.7 & 0.8 \\
\hline 42 & 1.2 & 90 & 0.125 & 1.5 & 0.3 & 0.5 \\
\hline 43 & 1.2 & 90 & 0.15 & 0.5 & 0.4 & 1.54 \\
\hline 44 & 1.2 & 90 & 0.175 & 0.75 & 0.5 & 1.27 \\
\hline 45 & 1.2 & 90 & 0.2 & 1 & 0.6 & 1.32 \\
\hline 46 & 1.2 & 95 & 0.1 & 1.5 & 0.4 & 0.87 \\
\hline 47 & 1.2 & 95 & 0.125 & 0.5 & 0.5 & 1.1 \\
\hline 48 & 1.2 & 95 & 0.15 & 0.75 & 0.6 & 0.78 \\
\hline 49 & 1.2 & 95 & 0.175 & 1 & 0.7 & 1.14 \\
\hline 50 & 1.2 & 95 & 0.2 & 1.25 & 0.3 & 0.87 \\
\hline
\end{tabular}




\subsection{Designing of the Neural Network Architecture}

The optimal neural network architecture 5-13-1 was used in this study is shown in Figure 2. It was designed using NeuroSolutions 4.0 software. The network consists of one input, one hidden and one output layer. The input layer has 5 neurons, hidden layer has thirteen neurons and output layer has one neuron respectively. Since surface roughness prediction in terms of nose radius, cutting speed, cutting feed, axial depth of cut and radial depth of cut was the main interest in this research, neurons in the input layer corresponding to the nose radius, cutting speed, cutting feed, axial depth of cut and radial depth of cut, the output layer corresponds to surface roughness.

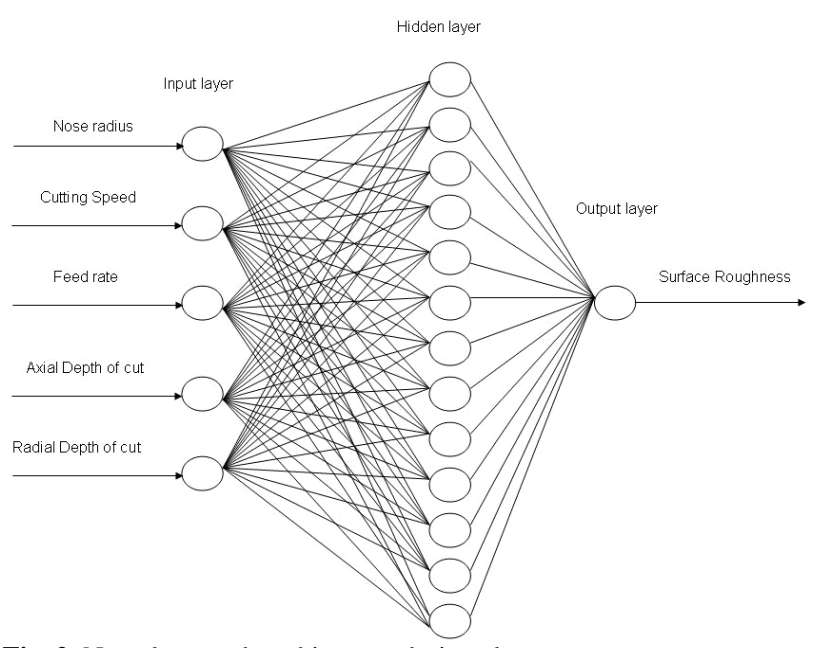

Fig. 2. Neural network architecture designed

\subsection{Generation of Train and Test Data}

To calculate the connection weights, a set of desired network output values are needed. Desired output values are called the training data set. The training data set in this study was created using Taguchi's $\mathrm{L}_{50}$ orthogonal array in the design of experiments. In this study, 50 data set were used for training and 12 data set were used for testing the network respectively and is given in Table 3 and Table 4.

Table 4. Data set used in testing ANN model

\begin{tabular}{lllllll}
\hline S.No & $\mathbf{R}$ & $\mathbf{V}$ & $\mathbf{f}$ & $\mathbf{d}$ & $\mathbf{r d}$ & $\begin{array}{l}\text { Measured } \\
\text { surface } \\
\text { roughness } \\
\text { (Ra, } \boldsymbol{\mu m})\end{array}$ \\
\hline 1. & 0.8 & 78 & 0.14 & 0.8 & 0.4 & 1.96 \\
2. & 0.8 & 78 & 0.14 & 0.8 & 0.4 & 1.96 \\
3. & 0.8 & 78 & 0.16 & 1.35 & 0.6 & 0.6 \\
4. & 0.8 & 87 & 0.14 & 1.35 & 0.6 & 0.78 \\
5. & 0.8 & 87 & 0.16 & 0.8 & 0.6 & 0.64 \\
6. & 0.8 & 87 & 0.16 & 1.35 & 0.4 & 1.02 \\
7. & 1.2 & 78 & 0.16 & 1.35 & 0.4 & 1.16 \\
8. & 1.2 & 78 & 0.16 & 0.8 & 0.6 & 1.56 \\
9. & 1.2 & 78 & 0.14 & 1.35 & 0.6 & 0.68 \\
10. & 1.2 & 87 & 0.16 & 0.8 & 0.4 & 1.24 \\
11. & 1.2 & 87 & 0.14 & 1.35 & 0.4 & 0.94 \\
12. & 1.2 & 87 & 0.14 & 0.8 & 0.6 & 1.18 \\
\hline
\end{tabular}

\subsection{Neural network training}

For calculation of weight variables, often referred to as network training, the weights are given quasi-random, intelligently chosen initial values. They are then iteratively updated until convergence to the certain values using the gradient descent method. Gradient descent method updates weights so as to minimize the mean square error (MSE) between the network prediction and training data set as in Eq. (5) and (6).

$$
\begin{aligned}
& \mathrm{W}_{\mathrm{i} j}{ }^{\text {new }}=\mathrm{W}_{\mathrm{i} j}{ }^{\text {old }}+\Delta \mathrm{W}_{\mathrm{ij}} \\
& \Delta \mathrm{W}_{\mathrm{ij}}=-\eta \sum_{\mathrm{t}=1}^{\mathrm{k}} \alpha^{\mathrm{k}-\mathrm{t}} \frac{\partial \mathrm{E}}{\partial \mathrm{W}_{\mathrm{ij}}} \text { out }_{\mathrm{j}}
\end{aligned}
$$

where $\mathrm{E}$ is the MSE and out $\mathrm{j}_{\mathrm{j}}$ is the $\mathrm{j}^{\text {th }}$ neuron output. $\eta$ is the learning rate [step size, momentum] parameter controlling the stability and rate of convergence of the network.. The learning rate [step size 1.0, momentum 0.7 ] selected and the training process takes place on a Genuine Intel x86 Family 6 Model 14 Stepping $12 \sim 17$ processor PC for 65,000 training iterations. The errors obtained after training of the network with 55914 epochs and multiple training (three times) are given in Table 5. The average of minimum mean square error and minimum mean square error is calculated for training data is $2.14342 \mathrm{E}-11$ and $1.64866 \mathrm{E}-11$ respectively. Figure 3 depicts the convergence of minimum MSE with epochs. The comparison between ANN model output and experimental output for training data sets are shown in Figure 4. Figure 4 showing that, the predicted values using ANN is very good correlation and representation with the experimental results.

Table 5. Error analysis of the network for surface roughness.

\begin{tabular}{lll}
\hline All Runs & $\begin{array}{l}\text { Training } \\
\text { Minimum }\end{array}$ & $\begin{array}{l}\text { Training } \\
\text { Standard } \\
\text { Deviation }\end{array}$ \\
\hline $\begin{array}{l}\text { Average of } \\
\text { Minimum }\end{array}$ & $2.14342 \mathrm{E}-11$ & $4.33946 \mathrm{E}-12$ \\
MSEs & & \\
Average of & $2.1454 \mathrm{E}-11$ & $4.31609 \mathrm{E}-12$ \\
Final MSEs & &
\end{tabular}

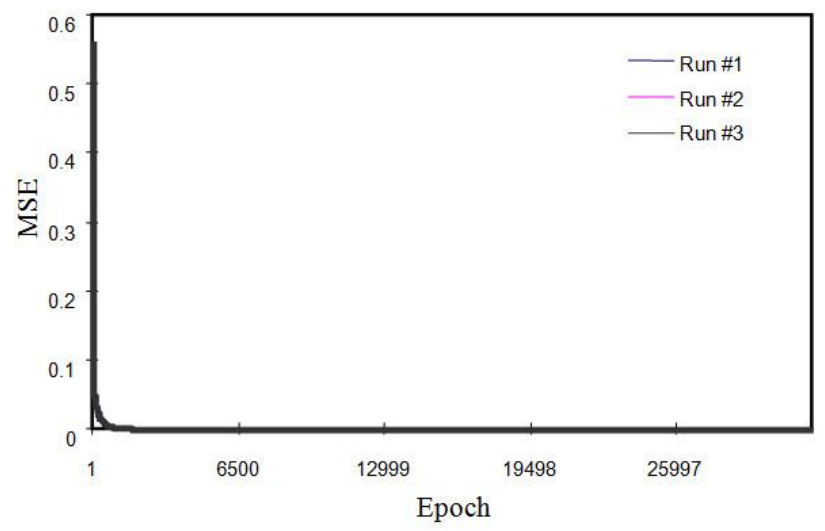

Fig. 3. Learning behaviour of ANN model for surface roughness 


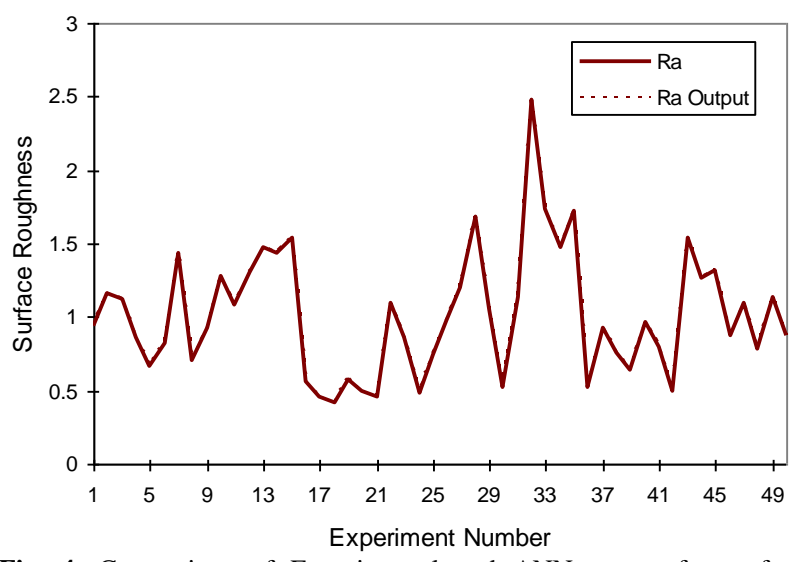

Fig. 4. Comparison of Experimental and ANN output for surface roughness

In order to judge the ability and efficiency of the model to predict the surface finish values percentage deviation (Ø) and the average percentage deviation $(\bar{\phi})$ were used and calculated as in Eq. (7) and (8)

$$
\phi_{\mathrm{i}}=\frac{\mid \text { Experimental }- \text { Predicted } \mid}{\text { Experimental }} \times 100 \%
$$

where $\phi_{\mathrm{i}}=$ percentage deviation of single sample data

$$
\bar{\phi}=\frac{\sum_{i=1}^{n} \varphi_{i}}{n}
$$

where $\bar{\phi}=$ average percentage deviation of all sample data and $n=$ size of the sample data. The percentage deviation and the absolute percentage deviation are shown in Figure 5. The average percentage deviation for surface roughness of training data calculated as $0.000178 \%$.

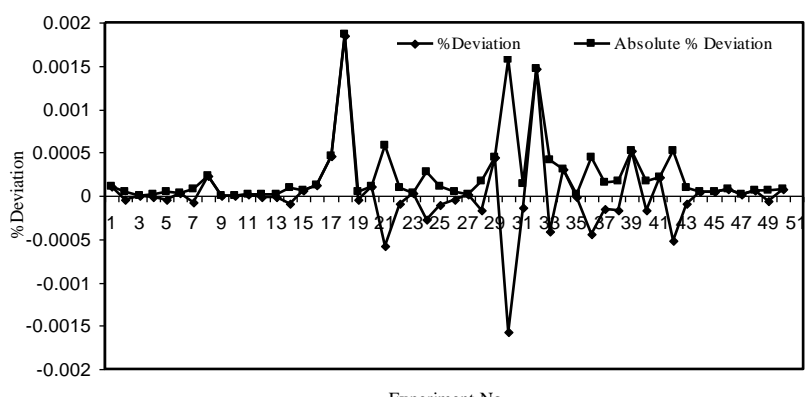

Experiment No.

Fig. 5. Percentage deviations of surface roughness (Training)

\subsection{Neural network testing}

The ANN predicted results are in very good agreement with experimental results and the network can be used for testing. Hence the testing data sets are applied for the network, which were never used in the training process. The results predicted by the network were compared with the measured values and shown in Figure 6. The percentage deviation and absolute percentage deviation is shown in Figure 7. The average percentage deviation for test data was found to be $4.716652 \%$.

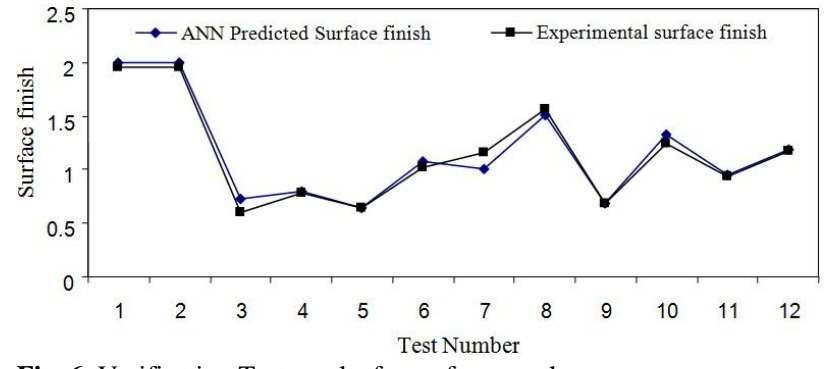

Fig. 6. Verification Test results for surface roughness

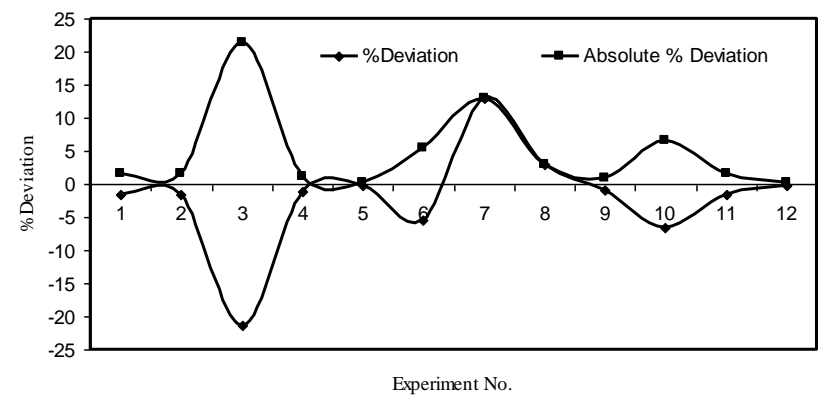

Fig. 7. Percentage deviations of surface roughness (Testing)

\subsection{Regression Analysis}

To have more precise investigation into the model, a regression analysis of predicted and measured values was performed and is shown in Figure 8. The adequacy of the developed model is verified by using coefficient of determination $\left(R^{2}\right) .0 \leq R^{2} \leq 1$. The $R^{2}$ is the variability in the data accounted for by the model in percentage [14].

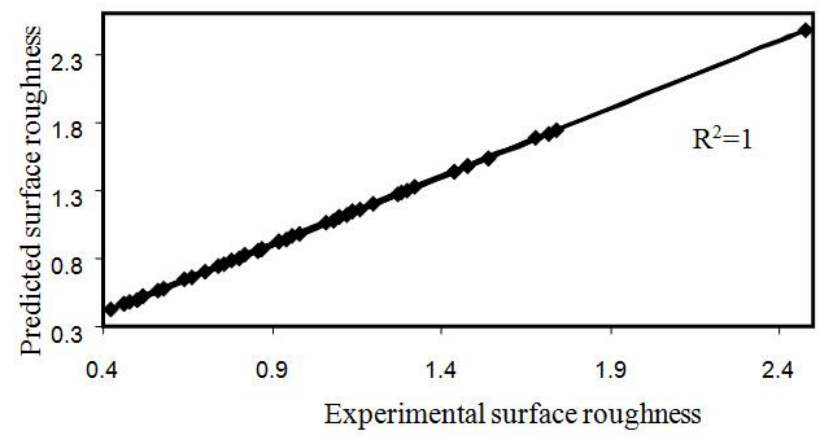

Fig. 8. Predicted outputs Vs measured outputs

The regression coefficient is calculated to estimate the correlation between the predicted values by the ANN model and the measured values resulted from experimental tests. The regression coefficient is calculated by using Eq. (9).

$R^{2}=1-\left[\frac{\sum_{j}\left(t_{j}-o_{j}\right)^{2}}{\sum_{j}\left(o_{j}\right)^{2}}\right]$ 
where $t_{j}=$ targets or experimental values or measured values, $\mathrm{o}_{\mathrm{j}}=$ outputs or predicted values.

There is a high correlation between the predicted values by the ANN model and the measured values resulted from experimental tests. The correlation coefficient for surface roughness was 1 , which shows there is a strong correlation in modeling surface roughness. From Figure 8 , it is very difficult to distinguish the best linear fit line from the perfect line, because the fit is so good.

\section{Parametric Analysis}

The sensitivity test was performed to obtain the variables that affect the surface roughness as shown in Figure 9. The test shows that feed rate is the most significant effect parameter on surface roughness followed by radial depth, nose radius, axial depth, and cutting speed. The variation of surface roughness for varied inputs is shown in Figures 1014. It is concluded that, the surface roughness increases with the increase of nose radius and cutting feed, because the increase of feed rate increased the heat generation and hence, tool wear which resulted in the higher surface roughness. The increase in federate also increased the chatter and produced incomplete machining at a faster traverse which led to higher surface roughness. The surface roughness decreases as the cutting speed, axial depth of cut and radial depth of cut increases. The reason being, at low axial depth of cut the material can't be removed fully which leads to high surface roughness. Whereas at high depth of cut the material is being clear of from the surface and produce good surface finish.

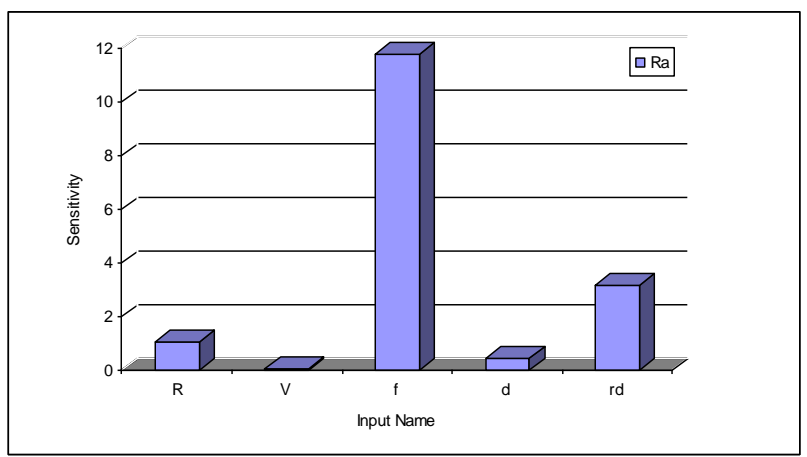

Fig. 9. Sensitivity test

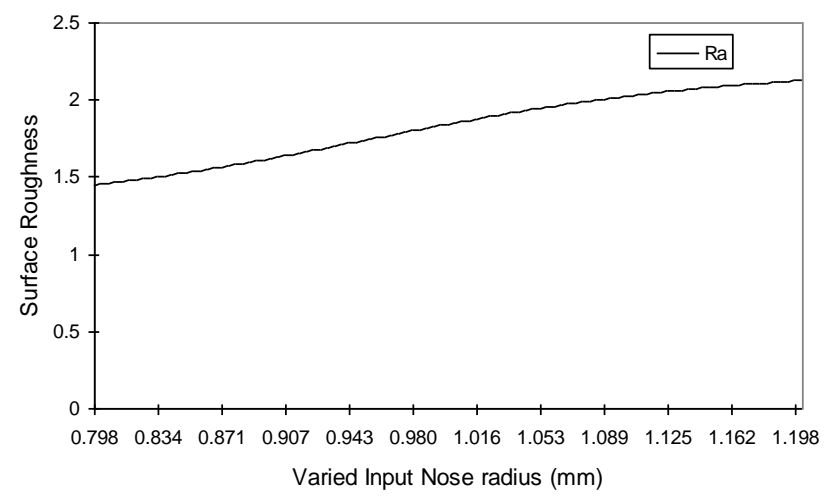

Fig. 10. Network Output(s) for Varied Input nose radius

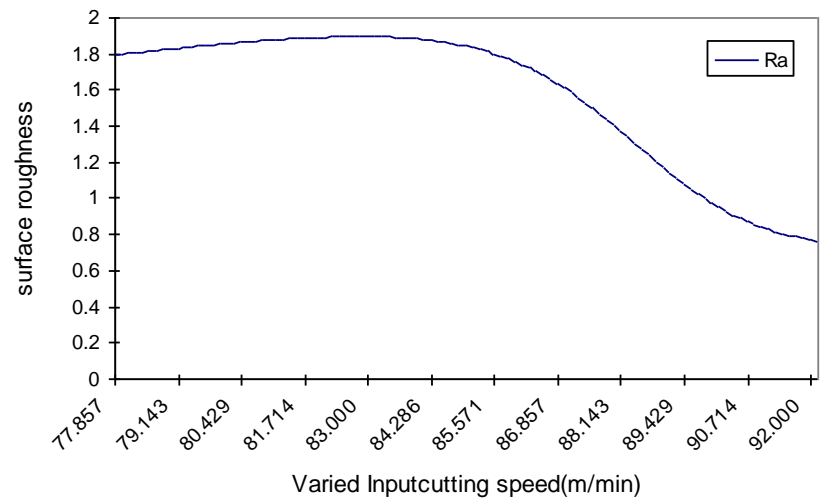

Fig. 11. Network Output(s) for Varied Input cutting speed

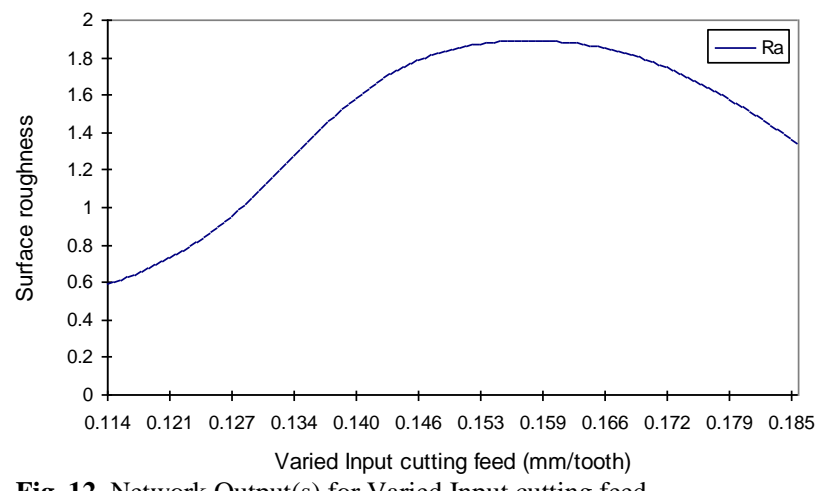

Fig. 12. Network Output(s) for Varied Input cutting feed

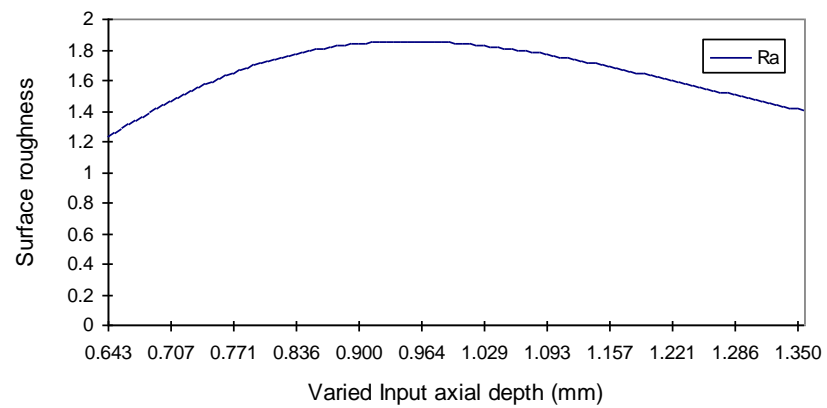

Fig. 13. Network Output(s) for axial depth (mm)

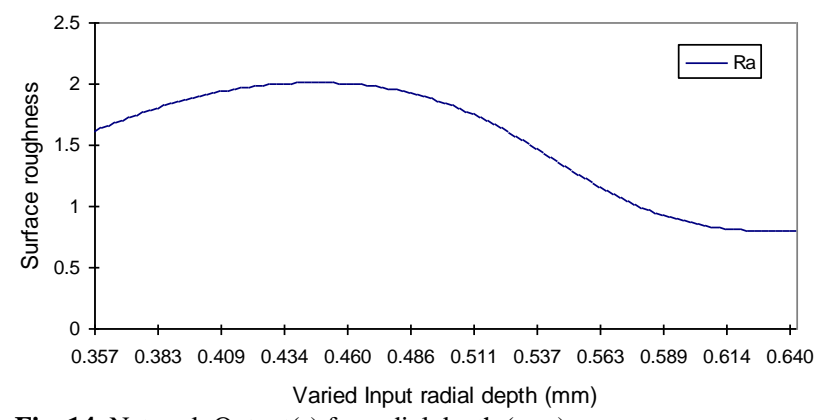

Fig. 14. Network Output(s) for radial depth (mm)

\section{Conclusions}

Using Taguchi's orthogonal array design in the design of experiments, the machining parameters which are influencing the surface roughness in end milling of P20 mould steel has been modeled using artificial neural 
networks. Based on experimental and ANN results, the following conclusions are drawn.

- The ANN predicted values are fairly close to the experimental values, which indicates that the developed model can be effectively used to predict the surface roughness of P20 mould steel.

- The feed rate is the most significant effect parameter on surface roughness followed by radial depth, nose radius, axial depth, and cutting speed.
- The ANN model could predict the surface roughness with average percentage deviation of $0.000178 \%$ from training data set.

- The ANN model could predict the surface roughness with average percentage deviation of $4.716652 \%$ from test data set.

- The correlation coefficient for surface roughness was 1 , which shows there is a strong correlation in modeling surface roughness.

\section{References}

1. Abbas Fadhel Ibraheem, Saad Kareem Shather and Kasim A. Khalaf, J. Eng.Tech. 26, 11, 1 (2008).

2. Muammer Nalbant, Hasan Gokkaya, and Ihsan Toktas, Modeling and Simulation in Engineering, 1 (2007), doi:10.1155/2007/92717.

3. R.A. Ekanayake and P. Mathew, Proc. 5th Australasian Congress on Applied Mechanics, ACAM 2007, 10-12 December 2007, Brisbane, Australia, pp.1-7 (2007).

4. M.A. Lajis A.N. Mustafizul KARIM, A.K.M. Nurul AMIN, A.M.K. HAFIZ and L.G. Turnad, European Journal of Scientific Research. 21, 4, 592 (2008).

5. Helen Coldwell, Richard Woods, Martin Paul, Philip Koshy, Richard Dewes, David Aspinwall, J. Mater. Process. Tech. 135, 301 (2003).

6. Mohammad Reza Soleymani Yazdi and Saeed Zare Chavoshi, Prod. Eng. Res. Devel. 4, 535 (2010), doi: 10.1007/s11740-0100232-7.

7. K. A Abou-El-Hossein, Kadirgama K, Hamdi M, Benyounis KY, J. Mater. Process. Technol. 182, 1-3, 241 (2007).
8. A.M. Khalid Hafiz, AKM Nurul Amin, ANM Mustafizul Karim and M.A. Lajis, , Proc. Int. Conf. on Mechanical Engineering 2007 (ICME2007) 29 - 31 December 2007, Dhaka, Bangladesh, pp.1-5 (2007).

9. M. Rahman, A. Senthil Kumar, and M.U. Salam, Int. J. Machine Tools and Manuf. 42, 5, 539 (2002).

10. M. Rahman, A. Senthil Kumar and U.I. Salem Manzoor, Int. J. Advanced Manuf. Tech. 18, 4, 235 (2001).

11. Y.S. Liao, and H.M. Lin, Mechanism of minimum quantity lubrication in high-speed milling of hardened steel, Int. J. Machine Tools and Manuf. 47, 11, 1660 (2007).

12. Neurosolutions 4.0 documentation available at http://www.neurosolutions.com/downloads/documentation.html.

13. D.C. Montgomery, Design and analysis of Experiments, fifth ed., Wiley, New York (2001).

14. Jadranka skorin-kapov and K. Wendy Tang, Int. J. Computing and information technology, 1, 1 (2001). 